\title{
Haroldo Quinteros: la forma-diario y los tiempos del testimonio
}

Haroldo Quinteros: the diary form and the different times of testimony

Jaume Peris Blanes

Universitat de València. España

jaume.peris@gmail.com

\section{RESUMEN}

El artículo analiza Diario de un preso político chileno, de Haroldo Quinteros, y su modo de encarar la experiencia vivida en diferentes prisiones y campos de concentración. Especialmente, la relación entre la estructura discursiva del "diario" y la doble y conflictiva temporalidad que atraviesa su escritura.

Palabras claves: Testimonio, Quinteros, exilio, campos de concentración, Chile.

\section{ABSTRACT}

The text focuses on Diario de un preso politico chileno (Haroldo Quinteros) and his way of bearing witness of his experience of prison and concentration camps. Specifically, the author focuses on the textual structure of the "diary" and his double experience of time.

Keywords: Testimony, Quinteros, exile, concentration camps, Chile.

Recibido: 04-09-2008 Aceptado: 26-09-2008

Diario de un preso político chileno, escrito por Haroldo Quinteros en el interior del campo de concentración de Iquique y en la Penitenciaría de Santiago a finales de 1973 y principios de 1974, es un libro singular en la producción testimonial chilena. Otros registros de supervivientes recurrieron a la forma textual del diario para dar cuenta de la experiencia vivida en los campos, pero el texto de Quinteros fue escrito en su interior y, aunque esa no 
fuera la función original del autor, consiguió capturar en él elementos esenciales del universo concentracionario chileno.

El objetivo de este artículo es contextualizar y analizar críticamente el modo en que la escritura de Quinteros, al contrario de la mayoría de la producción testimonial, trató de elaborar la experiencia límite de los campos de concentración en el mismo momento en que la estaba viviendo. En especial, el artículo se centra en el análisis de cómo esta escritura presenta una doble temporalidad y en cómo en las contradicciones, conflictos y fricciones que surgen entre ambas temporalidades narrativas, pueden leerse elementos importantes de la escritura testimonial en su conjunto (Agamben, 2000), acentuados por las excepcionales condiciones en que el autor elaboró su texto.

Para ello me valgo del análisis textual del libro, sirviéndome de las herramientas metodológicas desarrolladas en trabajos anteriores (Peris Blanes, 2005), y relaciono dicho texto con intervenciones contemporáneas, describiendo la manera en que dialoga con otras formas discursivas del momento, de acuerdo a la perspectiva histórica y social del testimonio trazada por Wieviorka:

El testimonio, sobre todo cuando se halla integrado en un movimiento de masas, expresa, además de la experiencia individual, el o los discursos que tiene la sociedad, en el momento en que el testigo cuenta su historia, sobre los acontecimientos que el testigo ha vivido. Dice, en principio, lo que cada individuo, cada vida, cada experiencia de la Shoa tiene de irreductiblemente único. Pero lo dice con las palabras que son propias de la época en que testimonia, a partir de un cuestionamiento y de unas expectativas que son también contemporáneas de su testimonio, asignándole finalidades dependientes de intereses políticos o ideológicos, contribuyendo así a crear una o más memorias colectivas, erráticas en su contenido, en su forma, en su función y en la finalidad, explícita o no, que ellas se asignan (1998: 13).

\section{DEL DIARIO TESTIMONIAL}

En los tiempos del exilio de los años setenta del siglo veinte, el diario fue una forma textual que sirvió a varios de los supervivientes de los centros de detención y tortura chilenos para la doble tarea de dar testimonio y elaborar en el discurso la experiencia extrema vivida en ellos. Entre los supervivientes que publicaron o expusieron sus testimonios en el exilio, Hernán Valdés, Guillermo Núnez y Haroldo Quinteros se sirvieron de la forma-diario para apuntar lo acontecido en prisiones y campos de concentración, aunque con estrategias de representación y presupuestos ideológicos muy diferentes.

Esta elección de la forma-diario resulta cuanto menos sorprendente, pues al hacer coincidir prácticamente la escena de enunciación con el objeto 
del enunciado, parece más difícil la ya de por sí compleja elaboración de la experiencia traumática en el discurso. Sin embargo, los tres supervivientes llevarían a cabo, cada uno a su manera, una sutil exploración de las contradicciones y límites de esa forma textual y de sus posibilidades expresivas e indagatorias.

En Tejas Verdes. Diario de un campo de concentración en Chile, Hernán Valdés (1974) se vale de un diario ficcional para, unas semanas después de su liberación del campo de concentración, tratar de reconstruir minuciosamente, con una estructura sintáctica en perpetuo presente, todo lo ocurrido en sus meses de encierro, filtrándolo a través de la conciencia del sujeto. Su narración extremadamente tensa y que llega a indagar con precisión en los mecanismos de desestructuración de la subjetividad que caracterizan a la tortura ${ }^{1}$, no tarda en convertirse en uno de los textos de referencia del exilio chileno y de sus luchas por hacer visible el carácter brutal y sistemático de la represión militar.

Por su parte, Diario de viaje de Guillermo Núnez (1974) hace un uso muy diferente de la forma-diario, directamente relacionado con la palabra poética y con la dialéctica de figuración-abstracción que domina su obra pictórica. Escrito también tras su liberación, tomando como material de base las cartas que le permitieron enviar al exterior y su memoria sensorial de ese episodio, su diario no reconstruye, como había intentado hacer Valdés, las situaciones vividas en el campo. Trata de capturar, a través de imágenes de gran ímpetu poético, algunas de las sensaciones experimentadas en esos días, pero sin hacer referencia directa -como sí hace en otras declaraciones, como su testimonio ante la UNESCO- a las situaciones reales sufridas en la Academia de Guerra de la Armada: "Voy atravesando el espejo y mi voz ya no tiene sonido / Estoy ciego en el túnel. Meto los dedos en el té frío y me aterrorizo" (VV. AA., 1993: 87).

Diario de un preso político chileno, publicado en Madrid por Haroldo Quinteros en 1979, era, de los tres, el único que podría llamarse, propiamente, un diario en el sentido tradicional del término, ya que efectivamente recoge las notas tomadas en forma de diario en el interior del campo de concentración de Iquique y en la Penitenciaría de Santiago entre el 5 de diciembre de 1973 y el 5 de febrero de 1974. En el prólogo de 1979 señala: "no he cambiado nada del original, ni he corregido notorias faltas de estilo. Es lo de menos. Este 'Diario' no fue escrito con ese propósito" (11). Vincula así el valor de su texto, como era

${ }^{1}$ Puede hallarse una reflexión mucho más detallada sobre las paradojas narrativas y ontológicas de la 'voz imposible' de Valdés en Peris Blanes (2005). Se trata, probablemente, del testimonio chileno en el que más claramente se evidencia la estructura del testimonio descrita por Agamben (2000: 137) como una subjetivación en una absoluta desubjetivación o, lo que es lo mismo, la construcción de una posición subjetiva desde la cual narrar el derrumbe de la propia subjetividad. 
lógico, a sus extraordinarias condiciones de escritura.

En él, Quinteros describe no sólo las situaciones experimentadas en los campos sino también algunas de las vicisitudes de su militancia anterior al golpe de Estado, vinculando en todo momento su situación de detenido con su condición de militante y tratando de reflexionar sobre los errores estratégicos de una izquierda cuyo proyecto histórico había sido derrotado por la violencia. Pero, además, y eso hace hermosamente singular a este texto, su escritura deja ver, aunque de forma elusiva, las dificultades materiales a las que se enfrenta a la hora de escribir al interior de los campos. Aunque éste no fuera el objeto del texto, sus desajustes, agujeros y lagunas narrativas dejan entrever una escena de escritura violentada, incapaz de suturar en un relato homogéneo una experiencia que no puede aparecer sino tremendamente fragmentada.

\section{LA ESCRITURA EN LOS CAMPOS DE CONCENTRACION}

Esa incapacidad de sutura ha sido, de hecho, una constante en distintas narraciones testimoniales (Dorfman, 1986), pero se halla especialmente acentuada en las diversas prácticas discursivas que tuvieron lugar en estos espacios violentados. Como diferentes supervivientes han atestiguado, algunas prácticas narrativas individuales o colectivas desempeñan un rol de importancia en la vida de los prisioneros. Es el caso de Rolando Carrasco, quien señala en Prigué (contracción de Prisionero de Guerra):

Encerrados desde las ocho de la noche hasta las siete de la mañana del día siguiente los 18 hombres en dos piezas de 4X4, comunicadas por el hueco de la puerta interior desaparecida, encontramos que una buena forma de postergar el aburrimiento consistía en rotar protagonizando un relato. Uno cada noche. Narración de absoluta libre elección y partiendo de la inspiración del de turno comenzaba en un momento cualquiera de la vida: recuerdos personales, sucesos vividos o escuchados, ensueños, planes; deslizando el borde exterior del presamiento, eludiendo remover costras todavía blandas. Terminaban con el agotamiento del tema o con los ronquidos de los auditores (1977: 131).

De ese modo, en aquellos campos en los que es posible organizar una cierta cotidianidad y los presos tienen la oportunidad de organizar actividades, la narración funciona, en algunos casos, como el pilar de nuevas formas compensatorias de la colectividad: un narrador se dirige a una comunidad de oyentes a los que entrega la puesta en relato de sus experiencias. Esa forma de comunidad surge, claro está, en unas condiciones enormemente precarias y 
hostiles, pero ello no hace sino reforzar el valor de esas prácticas como estrategia de supervivencia.

Tal como indica el testimonio de Carrasco, la estructura de esas reuniones parte, además, de una matriz organizativa que es, en sí, opuesta a la lógica general del campo: ningún tipo de relación jerárquica ordena la circulación de la palabra. Por el contrario, la estructura circular de las narraciones produce una distribución de las tomas de palabra que implica una participación real de todos los sujetos, en un espacio en el que los roles de narrador y oyente se intercambian. No se trata solamente de generar lazos comunitarios entre los detenidos, sino de hacerlo de un modo opuesto a aquel que ordena las identidades colectivas bajo el pinochetismo, es decir, que la producción discursiva no esté monopolizada por ningún componente del grupo, que sea democrática y participativa. El funcionamiento tiene como principio constructivo que todos los prisioneros accedan a la posibilidad de articular un discurso sobre la experiencia propia.

En un espacio en que la experiencia llega al punto límite de lo traumático, estas reuniones narrativas permiten que cada prisionero procure rearticular una posición como narrador de su propia experiencia. Intenta, así, construir de modo incipiente una posición de testigo que diga yo y ponga en relación a él una serie de acontecimientos en los que reconoce que su subjetividad se halla involucrada.

El hecho de que las vivencias al interior del campo no formen parte del material narrativo del que se nutren los relatos - "deslizando el borde exterior del apresamiento, eludiendo remover costras todavía blandas", señala Carrasco- es más que comprensible por su cercanía y carga traumática. No me parece gratuito pensar, sin embargo, que la experiencia radical que han vivido debió penetrar en esos relatos de otro modo. Si bien estas experiencias no son representadas explícitamente, se incluyen en esos relatos a través de su exclusión deliberada y consciente, lo que marca una preocupación extrema por aquello que todavía es demasiado sensible para permear el discurso, pero que está ahí, presionándolo desde fuera.

De manera similar, numerosos poemas escritos en el interior de los campos de concentración ${ }^{2}$ presentan elementos recurrentes, relacionados con la dificultad de enfrentarse a esta condición y hacerla inteligible poéticamente. Casi todos ellos exponen una curiosa estructura: ante una experiencia límite, borrosa y difícilmente enfocable, estos poemas crean otro espacio, imaginario,

${ }^{2}$ En Chacabuco, el Consejo de Ancianos llegó a convocar a un concurso de poesía en los primeros meses de 1974, al que se presentaron poco más de 40 y que contó con 10 poemas ganadores. 
irreal, desde el cual la vida en su interior puede ser representada con cierta distancia. Un espacio que se incluye en el poema por representación directa ${ }^{3}$ o por la figuración de un destinatario que está fuera de ese lugar y al cual se le relata lo que allí está ocurriendo ${ }^{4}$. Es necesario imaginar un punto de vista exterior al campo para hacer inteligible lo que ocurre en su interior.

\section{QUINTEROS Y LOS TIEMPOS DE LA ESCRITURA TESTIMONIAL}

Diario de un preso político chileno, de Haroldo Quinteros, hace frente a esas dificultades de otra manera. Su singularidad reside en el entrecruzamiento de dos temporalidades diferentes que entran en colisión a lo largo de todo el Diario. Desde el campo de Iquique -después de pasar por el Regimiento de Telecomunicaciones y por Pisagua en los meses de septiembre y octubre-, Quinteros intenta reconstruir narrativamente su experiencia desde el momento del golpe de Estado hasta llegar allí, y analiza todo lo sucedido en los campos anteriores. De ese modo, la temporalidad de la experiencia en el campo de Iquique, rigurosamente contemporánea del tiempo de la escritura, se entrecruza con la de la reconstrucción narrativa del pasado inmediato, que se ve continuamente interrumpida por la irrupción de la dinámica concentracionaria de Iquique y por las circunstancias que, en el momento de la escritura, afectan a Quinteros.

Esas continuas interrupciones, y la fragmentación narrativa que el texto presenta, hacen visible la dificultad del detenido para incluir su experiencia en una continuidad causal. Se trata de un problema típico de la escritura testimonial, que intenta dar un sentido temporal y vivencial a una condición traumática que aparece, en lo esencial, separada del resto de la vida del superviviente. Plantea Lawrence Langer en un libro ya clásico que

el testimonio es una forma de memoria (...) luchando contra lo que podemos llamar memoria disruptiva, es un esfuerzo de reconstruir algo similar a una continuidad en la vida como si fuera una existencia normal. La 'cotemporalidad' deviene el principio de esos testimonios, en tanto que el testigo lucha con la imposible tarea de hacer que sus reminiscencias del campo se articulen con el resto de sus vidas (Langer, 1991: 3).

3"Casas que estarán llenas de bullicio / juguetes y travesuras; de coquetería, artesa / y amorosos labios": "Casas de Chacabuco", de Jorge Montealegre, en Goldschmidt Wyman (2002: 113-115).

4"No puedo dejar de hablarte, padre / los diarios mienten, / todos mienten, / desde el boletín oficial,/ el periodista, / el impresor, / la tinta, / los avisos económicos, / la canillita, / a mí me fusilaron/ en la noche y a pleno campo /... no me arranqué": poema anónimo, reproducido en Goldschmidt Wyman (2002: 155). 
Por ello, la débil narratividad de la mayoría de estos testimonios no debe leerse como un fracaso estético, sino como una señal del modo en que los supervivientes tratan de articular en el discurso sus experiencias. De hecho, la mayoría de estos testimonios carece de una línea de continuidad causal que haga inteligibles las relaciones entre unos y otros elementos narrativos. En definitiva, lo que falta en gran parte de estos textos es un sujeto fuerte capaz de suturar con su presencia la disgregación de los diversos aspectos que está poniendo en juego en su relato. Esta característica nos habla de dos cuestiones fundamentales: en primer lugar, los acontecimientos se presentan fragmentados a los supervivientes y, en segundo lugar, al elaborar narrativamente esa experiencia, los supervivientes no hallan la forma, en la mayoría de los casos, de integrar esos elementos disgregados en una narración unitaria 5 .

En el caso del texto de Quinteros, la urgencia de la escritura en el interior de la prisión hace, si cabe, más visible sus dificultades para unificar la experiencia en una trama causal con coherencia narrativa. De hecho, más que tratar de consignar lo cotidiano en Iquique, el Diario se propone como tarea reconstruir el recorrido y las vivencias que le han llevado hasta allí, dando un lugar secundario a los elementos de la inmediatez del campo:

Iquique, 5 de diciembre 1973.

Anteayer llegamos a Iquique, y es la primera vez que puedo escribir. Tenía unos deseos enormes de hacerlo, desde Pisagua. ¿`Por dónde empezar? Estoy cansado, pero no apagan la luz de la celda, he conseguido papel y lápiz y tampoco puedo dormir. (...) Si tuviera que empezar de alguna forma tendría que ser desde el comienzo de mi vida, por lo menos desde el comienzo de mi vida en política, desde que era un adolescente. Sé, sin embargo, que tendré tiempo de sobra para esos detalles, y me urge hablar de lo que ha ocurrido ahora último (1979: 20).

Si bien el objetivo declarado del diario es reconstruir narrativamente un trayecto, las condiciones de vida en el campo aparecen, aunque lateralmente, al señalar las limitaciones en que se lleva a cabo la escritura. Quinteros intenta trabar narrativamente los episodios ocurridos desde el día anterior al golpe de Estado hasta el momento de la escritura. El objeto de su discurso es fundamentalmente ideológico, por lo que vincula directamente su condición de activista popular al hecho de convertirse en objeto de la represión. Así, el relato de su detención es precedido por las reuniones de deliberación con otros

${ }^{5}$ Desde un punto de vista teórico, las contradicciones de la enunciación testimonial están analizadas en Peris Blanes (2005) siguiendo las ideas de Agamben (2000 y 2004) y Derrida (2005) y criticando su deshistorización del testimonio a la luz de las aportaciones de Wieviorka (1998). 
miembros del Partido Socialista de Iquique en las que trataban de hallar alguna solución al Golpe inminente que ya en los días anteriores se anunciaba.

A pesar de ese objetivo reconstructivo, las primeras notas (más de tres páginas) tomadas en la noche de ese 5 de diciembre, y en las que se asientan los antecedentes del relato, se cierran de nuevo con la emergencia de las condiciones del campo y violentan por completo la escena de escritura:

Ya es imposible seguir ahora. Es raro que nos dejen solos. Estoy seguro de que esto va a cambiar. Pero ya todos duermen y yo no doy más. Seguiré mañana. Por lo menos hay dónde y cómo 'fondear' estos papeles (1979: 22).

Ese choque de temporalidades diferenciadas atraviesa todo el Diario, dando la impresión de que la reconstrucción narrativa de la experiencia en el Regimiento de Telecomunicaciones y en Pisagua tienen como objetivo siempre demorado alcanzar el tiempo en que se desarrolla la escena de la escritura. Ésta, sin embargo, interrumpe constantemente a la otra a través de insertos recurrentes, como el resto no declarado de una realidad que el prisionero decide no afrontar directamente, sino que pretende darle sentido narrando las experiencias que le precedieron.

Diversos elementos interconectan, sin embargo, esas dos temporalidades: "Esa noche comenzó un resfriado que luego se transformaría en bronquitis cuyas secuelas todavía me duran (6 de diciembre)" (1979: 27). Poco a poco, el tiempo de la escritura gana espacios en el texto, localizándose especialmente en los párrafos inicial y final de cada jornada del diario, pero presentándose siempre como un elemento secundario para los intereses de Quinteros, subordinado a la reconstrucción narrativa que está realizando: "El número de presos ha aumentado de tal manera que apenas nos dan una sopa aguada con una papa o un hueso. Pero en fin, ya hablaremos de eso. Seguiré con Pisagua (8 de diciembre)" (1979: 35); "Después de solucionar problemas de papel y de dejar de escribir unos días para evitar las continuas frasecitas: '¿qué escribes tanto?', prosigo. Después de todo, es lo único que podemos hacer aquí y además debo hacerlo (15 de diciembre)" (1979: 42).

\section{DERROTA POLÍTICA Y DUELO IMPOSIBLE EN LA ESCRITURA TESTIMONIAL}

Del otro lado, el proyecto narrativo que tiene como objeto la experiencia anterior al internamiento en Iquique pone un especial énfasis en la reconstrucción del ambiente ideológico de la izquierda vinculada a la Unidad 
Popular, tanto en las horas anteriores al Golpe como en sus intercambios en el interior de los campos de Telecomunicaciones y Pisagua. De hecho, Quinteros reconstruye en sus notas las conversaciones, discusiones y análisis desarrollados en común con sus compañeros, tomando todo ello como elementos de base para un análisis ideológico y crítico de los errores del proyecto popular y de las razones de emergencia del 'fascismo'

Así, sus diarios son en buena parte un hilado de conversaciones en las que se expresan los puntos de vista de las diversas militancias, al tiempo que plantea los posibles marcos de interpretación del proceso que está teniendo lugar y las experiencias históricas que pueden servir de referencia para experiencias futuras, llegando a proponerse, en diferentes ocasiones, el proyecto maoísta como eje a partir del cual pensar el proceso socialista en las economías periféricas.

Como varios de los testimonios publicados en el exilio, el texto de Quinteros se propone como el espacio en que puede resguardarse lo esencial de aquello que la violencia militar ha cercenado. No sólo la lucha social, sino también la concepción de la experiencia, de la comunidad y de las relaciones humanas que había vertebrado el proyecto popular y que la brutal represión militar estaba tratando de desarticular?

En ese sentido, la escritura de Quinteros es, como la de otros muchos detenidos, una escritura doliente $y$, en un sentido amplio, fuertemente melancólica. Incapaz de realizar el duelo por la derrota histórica que el régimen militar ha infligido al proyecto de la 'vía chilena al socialismo', la escritura se convierte en un espacio de reparación. No solamente en un lugar en el que la experiencia política que había definido al tiempo de la Unidad Popular puede ser resguardada, sino en el que, además, ésta puede tener continuidad (Unnold, 2002).

La narración en la que toma cuerpo ese proyecto se debate entre su voluntad de organicidad y la presencia de numerosos hiatos narrativos. Su continuidad se halla, de hecho, recurrentemente entrecortada por la emergencia de la escena en que se desarrolla la escritura, desvelando la profunda dificultad de Quinteros para organizar una relación narrativa que haga inteligible su situación en tanto preso:

${ }^{6}$ Esa denominación a todas luces inexacta para categorizar al régimen militar chileno sirvió, sin embargo, en los primeros tiempos, para cohesionar las luchas contra él integrándolas en el paradigma internacional del antifascismo.

${ }^{7}$ Hay un análisis detallado de la función desempeñada por los testimonios de supervivientes en el exilio en Peris Blanes (2008). Esa función debería vincularse con la crisis de la intelectualidad latinoamericana a finales de los años sesenta y setenta y el auge del antiintelectualismo, que darían un espacio de legitimidad al testimonio frente a las intervenciones de los intelectuales tradicionales (Gilman, 2003). 


\section{3 de diciembre.}

Se me ha armado una confusión terrible. He escrito ayer nuestras aventuras en la cárcel de Iquique, y para no perder el hilo las continuaré. El relato de Pisagua esperará hasta mañana, o cuando se pueda. Quizás tenga que cortarlo definitivamente. Ya han empezado seriamente los trabajos en la medida que he anotado ayer. Me ha dado por trabajar la madera y eso me hace descansar mucho, 'tomar caldo de cabeza' en menor cantidad, y con suerte hasta podría vender algo, a través de la Iglesia. Pero en fin, seguiré con los otros papeles (1979: 22).

De ese modo, la propia escritura se convierte en espacio y en objeto de reflexión sobre sí misma, tematizando el proceso de elaboración de la experiencia que en ella tiene lugar, frente a otras actividades que permiten al prisionero suspender el carácter asfixiante de la dinámica concentracionaria. Quinteros alude, incluso, al desfasaje entre las dos temporalidades a las que he hecho referencia anteriormente, señalándolo como uno de los elementos fundamentales de la relación del prisionero con su escritura. De hecho, poco a poco los insertos que hablan de la situación inmediata de Iquique se hacen cada vez más presentes ${ }^{8}$, sin embargo, el hiato entre ambas experiencias aún se mantiene, sin que la reconstrucción narrativa alcance nunca la temporalidad del momento de escritura. Es más, es el mismo día en que Quinteros da cuenta del inminente traslado desde Iquique hacia la Penitenciaría de Santiago ("Acaban de comunicarnos que mañana nos llevan a Santiago, a la Penitenciaría. 28 de enero, 84") cuando el escritor muestra su interés explícito por describir la dinámica de Iquique, aunque lo hace de forma más que peculiar, complejizando aún más el cruce de temporalidades del Diario:

Todos estos días no he hecho nada sino entretenerme haciendo figuritas de madera y dibujos. Escribir me ha cansado, y hasta me puso sumamente tenso durante la primera quincena de enero. Creo que aquí dejaré de escribir, y quizás, si se puede, seguiré en Santiago. Agregaré al orden que hago de estas hojas, una que escribí el 22 de diciembre. Aquí está:

22 de diciembre.

Ya está bueno que hable de esta cárcel de Iquique. Estamos hacinados en una

8"Hoy, cuatro de enero, Nora cumple 26 años, y no tengo nada que darle. Mañana, día de visita, deberá conformarse con verme. Pobre mi mujer, cuando le dije el primer día que nos vimos, después de casi cuatro meses de dolorosa separación, que se considerase libre, que preso sólo estaba yo y no ella, que podrían pasar muchísimos años de cárcel o hacerme desaparecer, que tratara de rehacer su vida, me dio un bofetón y lloró amargamente, más amargamente que cuando le dijeron que había sido fusilado. Me dijo 'contigo están presos todos sus seres queridos, y yo más que todos'. Aunque sé que siempre la quise mucho, esa vez creo que lo supe realmente. Supongo que en eso consiste el castigo que me impone la burguesía, y nada más: el privarme de ella. 4 de enero, 54”. 
sola celda, digamos, unos 40 presos políticos. Pero es mejor que en Pisagua. En el día no hago sino conversar con los presos comunes, para conocerlos... 4 de enero (1979: 84).

Ya en la jornada del 23 de diciembre, como puede leerse más arriba, Quinteros ha consignado la existencia de estas páginas destinadas a la descripción de Iquique: "Se me ha armado una confusión terrible. He escrito ayer nuestras aventuras en la cárcel de Iquique, y para no perder el hilo las continuaré" (1979: 44), pero es sintomático que sea sólo en ese momento, cuando se anuncia su traslado a la Penitenciaría de Santiago, que decide incluirlas en el Diario, como una manera, quizás, de taponar ese hiato omnipresente entre la reconstrucción narrativa de su llegada hasta allí y la emergencia de elementos que hacen referencia a las condiciones en que se desarrolla la escritura: como si ambas, en la dinámica del texto, no puedan nunca coincidir.

Ese continuo diferimiento del encuentro entre ambas temporalidades creo que da cuenta de la dificultad, por una parte, de enfrentar directamente la experiencia de la dinámica concentracionaria en el momento en que está siendo vivida y, por otra, de la imposibilidad de reconstruir la experiencia reciente sin que algo de esa realidad inasumible haga acto de presencia en el discurso, produciendo cortocircuito en su ilación narrativa, a través de la emergencia de esos restos precarios y desarticulados de la conflictiva situación de escritura.

\section{CONCLUSIONES}

El Diario condensa, pues, algunos de los problemas mayores que los supervivientes deben enfrentar a la hora de poner en discurso su experiencia. Al escribir desde el interior mismo del campo de concentración, la escritura de Quinteros expresa buena parte de los impasses que encuentra el superviviente al tratar de poner en discurso el acontecimiento traumático.

Si otros supervivientes eligieron la forma-diario para registrar la experiencia en el campo a un punto máximo de tensión, el diario real de Quinteros da cuenta de una tensión mayor entre la experiencia vivida y la posibilidad de representarla mediante la escritura. La doble y conflictiva temporalidad de esas páginas es un índice textual de la imposibilidad de cercar plenamente la situación límite de los campos en el espacio de la escritura. Las fricciones e interrupciones entre ambas temporalidades textualizan no sólo la violencia del ominoso escenario en que tiene lugar la escritura sino, además, las dificultades del sujeto para integrar las vivencias traumáticas en un discurso con continuidad capaz de hacerlas inteligibles. Ello no es de extrañar, pues los presos, como más 
tarde harán los supervivientes, se enfrentan a un reto de apariencia imposible y que constituye en sí el desafío mayor de la enunciación testimonial: construir una posición (subjetiva) para hablar sobre el proceso mismo que amenaza con derruir por completo su subjetividad y hacerlo, además, desde el interior de ese derrumbe.

\section{REFERENCIAS}

Agamben, Giorgio. 2000. Lo que queda de Auschwitz. El archivo y el testigo. Homo Sacer III. València: Pre-Textos. . 2004. Estado de excepción. Homo sacer II. València: Pre-Textos.

Carrasco, Rolando. 1977. Prigué. Moscú: Novosti.

Derrida, Jacques. 2005. Poétique et politique du témoignage. Paris: L'Herne.

Dorfman, Ariel. 1986. "Código político y código literario: el género testimonio en Chile hoy", en Testimonio y literatura. Jara, René; Vidal, Hernán. Minessota: Institute for the Studies of Ideologies and Literature, pp. 170-234.

Gilman, Claudia. 2003. Entre la pluma y el fusil. Debates y dilemas del escritor revolucionario en América Latina. Buenos Aires: Siglo XXI.

Goldschmidt Wyman, Eva (ed.). 2002. Los poetas y el General. Voces de oposición en Chile bajo Augusto Pinochet 1973-1989. Santiago de Chile: LOM.

Langer, Lawrence L. 1991. Holocaust testimonies. The ruins of memory. New Haven y London: Yale University Press.

Peris Blanes, Jaume. 2005. La imposible voz. Memoria y representación de los campos de concentración en Chile: la posición del testigo. Santiago de Chile: Cuarto Propio. 2008. Historia del testimonio chileno. De las estrategias de denuncia a las politicas de memoria. València: Anejos de Quaderns de Filologia.

Quinteros, Haroldo. 1979. Diario de un prisionero politico chileno. Madrid: Ediciones de la Torre.

Unnold, Yvonne S. 2002. Representing the unrepresentable. Literature of trauma under Pinochet in Chile. New York: Peter Lang.

Valdés, Hernán. 1974. Tejas Verdes. Diario de un campo de concentración en Chile. Barcelona: Ariel.

VV.AA. 1993. Guillermo Núnez. Retrato hablado. Una retrospectiva. Santiago de Chile. Museo de Arte Contemporáneo.

Wieviorka, Annette. 1998. Lère du témoin. París: Plon. 